\title{
Legacy Drug Prescribing Patterns in Primary Care: A Cohort Study
}

\author{
Paula P. Amin, MD, Grant Family Medicine Residency \\ Michael E. Jobansen, MD, MS, Associate Editor
}

Ann Fam Med. 2018;16(6):iii. https://doi.org/10.1370/afm.2324.

The Annals of Family Medicine encourages readers to develop a learning community to improve health care and health through enhanced primary care. Participate by conducting a RADICAL journal club. RADICAL stands for Read, Ask, Discuss, Inquire, Collaborate, Act, and Learn. We encourage diverse participants to think critically about important issues affecting primary care and act on those discussions. ${ }^{1}$

\section{HOW IT WORKS}

In each issue, the Annals selects an article and provides discussion tips and questions. Take a RADICAL approach to these materials and post a summary of your conversation in our online discussion. (Open the article and click on "TRACK Discussion/ Submit a comment.") Discussion questions and information are online at: http://www.AnnFamMed.org/site/AJC/.

\section{CURRENT SELECTION}

\section{Article for Discussion}

Mangin D, Lawson J, et al. Legacy drug prescribing patterns in primary care. Ann Fam Med. 2018;16(6):515-520.

\section{Discussion Tips}

Cohort studies allow researchers to explore associations and trends in how medical care is provided, which can lead to important insights about improving care such as continuing medications longer than is frequently recommended. This retrospective cohort study evaluated over 50,000 patients from a variety of clinicians to describe longitudinal prescribing patterns of antidepressants, bisphosphonates, and PPIs to identify and describe the phenomenon of "legacy prescribing."

\section{Discussion Questions}

- What question is asked and why does it matter?

- What is a retrospective cohort study? How does this differ from a prospective cohort study and a casecontrol study?
- How does this study advance beyond previous research and clinical practice on this topic?

- How strong is the study design for answering the question and what are the weaknesses?

- How does the sum duration calculation differ from the start-stop calculation? What insight can be gained from looking at the supplementary appendix?

- To what degree can the findings be accounted for by: how patients were selected or excluded ${ }_{i}$ how the main variables were measured ${ }_{\text {; }}$ confounding (false attribution of causality because 2 variables discovered to be associated actually are associated with a 3 rd factor) ${ }_{i}$ chance; or how the findings were interpreted?

- What are the main study findings?

- How do the findings of legacy prescribing of bisphosphonates compare with the findings of PPIs and antidepressants? Why might these rates differ?

- Have you talked with a patient about stopping any of these medications? How are the conversations different than those about starting medication?

- How strong is the evidence against long-term use of the included drug classes? Are these cases of lack of evidence or strong evidence against?

- How comparable is the study sample to similar patients in your practice? What is your judgment about the transportability of the findings?

- What other medication classes more commonly prescribed in primary care may have similar legacy prescribing trends?

- How might this study change your practice? Policy? Education? Research?

- What are the next steps in interpreting or applying the findings?

- What researchable questions remain? How might a qualitative component improve your understanding of this phenomenon?

\section{References}

1. Stange KC, Miller WL, McLellan LA, et al. Annals Journal Club: It's time to get RADICAL. Ann Fam Med. 2006;4(3):196-197. 